\title{
Genotoxicity of the Organophosphorus Insecticide Chlorpyrifos Based on Human Lymphocyte Culture
}

\author{
Mark C. Nelson ${ }^{1}$, S. M. Jalal ${ }^{1}$ and Omer R. Larson ${ }^{2}$ \\ ${ }^{1}$ Cytogenetics Laboratory, Texas Genetic Screening and Counseling \\ Services, P. O. Box 2467, Denton, Texas 76202 U.S.A. \\ ${ }^{2}$ Department of Biology, University of North Dakota, Grand Forks, \\ North Dakota 58202 U.S.A.
}

Accepted May 11, 1990

Chlorpyrifos,O,O-diethyl-O-(3,5,6-trichloro-2-pyridyl)phosphorothioate is a broad spectrum insecticide, marketed under the names Dursban, Lorsban and DOWCO 19. Organophosphorus compounds such as chlorpyrifos are popular insecticides because of their effectivencess as cholinesterase inhibitors, high degree of water solubility and rapid biodegradation. However, many of these compounds and their breakdown products are known alkylating agents of DNA (Bedford and Robinson 1972). It is therefore imperative to continue to assess potential genetic damage from limited exposure to organophosphorus insecticides (Degraeve et al. 1984).

\section{Materials and methods}

Peripheral blood while fasting was used from three non-smoking healthy adults. Their GTG banded karyotypes were normal. Total volume of $8.0 \mathrm{ml}$. was attained by using $7.1 \mathrm{ml}$. of Difco chromosome culture medium, $0.8 \mathrm{ml}$. of fresh whole blood and $0.1 \mathrm{ml}$. of DMSO (dimethyl sulfoxide) with or without treatments. Four treatments $(0.02,0.2,2.0,20 \mu \mathrm{g} / \mathrm{ml})$ of chlorpyrifos and two controls (no treatment and $0.1 \mathrm{ml}$. DMSO) were used in close accord with Preston et al. (1981) protocol. Chlorpyrifos (>99\% pure) was provided by the U.S. Environmental Protection Agency. All solutions were prepared within 48 hours of their use. Four-hour exposure was used for assessment of the chromosome damage from direct action of the compound, and 24-hour exposure was used to detect indirect interactions of chlorpyrifos and its metabolities (Bloom 1981). Single replication of sister chromatid exchanges (SCE) from 24-hour exposure in $10 \mu \mathrm{g} / \mathrm{ml}$ of $\mathrm{BrdU}$ (5-Bromodeoxyuridine) was used for mutagenicity testing, using the Latt et al. (1979) method.

Standard culture technique for the whole blood was used at $37^{\circ} \mathrm{C}$ for 72 hours in a Labline $\mathrm{CO}_{2}$ incubator. Slide labels were disguised while taking the data by a Zeiss Photomicroscope III. Data were taken from 50 cells per treatment and controls giving a total of 150 cells per replication of 4- and 24-hour treatments. Data for the clastogenic and mutagenic studies were analyzed using ANOVA and Dunnett's multiple comparison test. Dunnett's test is most applicable when comparing a control group to one or more experimental groups (Roscoe 1975). Since treatments spanned more than one order of magnitude, $\log$ transformed data was also analyzed (Margolin 1985).

${ }^{1}$ Formerly from Department of Biology, University of North Dakota, Grand Forks, North Dakota 58202. This study was supported in part by the NSF grant (PRM 81-20271) to S. M. Jalal, Ph. D. Please forward reprint requests to Dr. S. M. Jalal. 


\section{Results and discussion}

The most common chromosome aberrations observed from chlorpyrifos exposure were interstitial gaps and breaks. Most aberrations were single events in individual cells, Thus, the means are not skewed results from a few cells with large numbers of aberrations.

The summary of three 4-hour replications ( 150 calls per replication) is presented in Table 1 . The two controls exhibited the smallest numbers of gaps, breahs and gaps plus breaks. Chromosome damage tended to increase slightly (statistically nonsignificant) as the concentrations

Table 1. Chromosome aberrations per cell in Chlorpyrifos treated human lymphocytes, 4-hour exposure summary

\begin{tabular}{lcccc}
\hline \hline $\begin{array}{c}\text { Concentration } \\
(\mu \mathrm{g} / \mathrm{ml} \text { Chlorpyrifos })\end{array}$ & Gaps & Breaks & $\begin{array}{c}\text { Gaps plus } \\
\text { breaks }\end{array}$ & $\begin{array}{c}\text { Abnrmal cells } \\
(\%)\end{array}$ \\
\hline No treatment control & 0.060 & 0.047 & 0.107 & 10.7 \\
DMSO control & 0.053 & 0.033 & 0.086 & 8.6 \\
0.02 & 0.080 & 0.040 & 0.120 & 12.0 \\
0.2 & 0.080 & 0.047 & 0.127 & 12.7 \\
2.0 & 0.080 & 0.053 & 0.133 & 13.3 \\
20.0 & 0.060 & 0.060 & 0.120 & 12.0 \\
F value & & & 2.278 & \\
Df $^{2}$ & & & 1,16 & \\
F value $^{3}$ & & 4.49 & \\
\hline
\end{tabular}

Means are based on 150 cells per treatment.

${ }^{1}$ Calculated $\mathbf{F}$ value.

${ }^{2}$ Degrees of freedom for the replicate.

${ }^{3}$ Table value which $\mathrm{F}$ must equal or exceed to be statistically significant $(\mathrm{P}<0.05)$.

Table 2. Chromosome aberrations per cell in Chlorpyrifos treated human lymphocytes, 24-hour exposure summary

\begin{tabular}{lcccc}
\hline $\begin{array}{c}\text { Concentration } \\
\text { ( } \mu \text { g/ml Chlorpyrifos) }\end{array}$ & Gaps & Breaks & $\begin{array}{c}\text { Gaps plus } \\
\text { Breaks }\end{array}$ & $\begin{array}{c}\text { Abnormal cells } \\
(\%)\end{array}$ \\
\hline No treatment control & 0.067 & 0.047 & 0.114 & 11.4 \\
DMSO control & 0.053 & 0.047 & 0.100 & 10.0 \\
0.02 & 0.040 & 0.033 & 0.073 & 7.3 \\
2.0 & 0.087 & 0.047 & 0.134 & 13.4 \\
20.0 & 0.053 & 0.080 & 0.133 & 13.3 \\
F value & & & 1.010 & \\
Df $^{2}$ & & & 1,16 & \\
F value $^{3}$ & & 4.49 & \\
\hline
\end{tabular}

Means are based on 150 cells per treatment.

1 Calculated $F$ value.

${ }^{2}$ Degrees of freedom for the replicate.

${ }^{3}$ Table value which $F$ must equal or exceed to be statistically significant $(P<0.05)$.

of chlorpyrifos increased, reaching a peak of 0.133 gaps plus breaks per cell at $2.0 \mu \mathrm{g} / \mathrm{ml}$ level. The aberration levels between the two controls and between the three donors were also nonsignificant.

The summary of three 24-hour replications is presented in Table 2. The smallest number of gaps, breaks and gaps plus breaks occurred at $0.02 \mu \mathrm{g} / \mathrm{ml}$ followed by the DMSO control. The aberration levels increased slightly, reaching a peak at 2.0 and $20.0 \mu \mathrm{g} / \mathrm{ml}$ where the values for gaps and breaks per cell were 0.134 and 0.133 , respectively. The observed pattern of chromosome damage was nonsignificant and generally quite similar to the 4-hour exposure results. 
The lack of significant increases from the treatments ranging from 0.02 to $20 \mu \mathrm{g} / \mathrm{ml}$ both in 4 hour and 24-hour exposures indicates that chlorpyrifos and its metabolities have a limited, if any, influence in increasing chromosome aberrations. This is in agreement with the findings of Muscarella et al. (1984) and Thompson et al. (1971), who reported chlorpyrifos to be nonclastogenic in small mammals, and those of Sobti et al. (1982), who observed the compound to be nonclastogenic in humans.

Sister chromatid exchanges, based on the average of 25 cells each for the two controls were compared with the four treatment levels (Table 3). No treatment control had statistically nonsignificant differences compared to all four treatment levels. The DMSO control had a nonsignificant difference at $0.2,2.0$ and $20.0 \mu \mathrm{g} / \mathrm{ml}$ concentration levels, and a significant increase at $0.02 \mu \mathrm{g} / \mathrm{ml}$ level. Compared to the DMSO control all treatment levels had enhanced $\mathrm{SCE}$ values, though only at $0.02 \mu \mathrm{g} / \mathrm{ml}$ it reached significance. Thus, results of this investigation do not depict chlorpyrifos as an agent that results in consistent increase of SCE levels, at these dosages. However, Sobti et al. (1982) have reported increased SCE levels at 2.0 and $20.0 \mu \mathrm{g} / \mathrm{ml}$ of chlorpyrifos in human lymphocytes in culture. Chen et al. (1981) did not observe

Table 3. Sister Chromatid Exchange in Chlorpyrifos treated human lymphocytes

\begin{tabular}{lcc}
\hline \hline $\begin{array}{c}\text { Concentration } \\
(\mu \mathrm{g} / \text { ml Chlorpyrifos })\end{array}$ & $\begin{array}{c}\text { Number of exchanges } \\
\text { observed }\end{array}$ & $\begin{array}{c}\text { Mean number per } \\
\text { cell }(\%)\end{array}$ \\
\hline No treatment control & 151 & 6.04 \\
DMS control & 119 & 4.76 \\
0.02 & $165^{*}$ & $6.60^{*}$ \\
0.2 & 124 & 4.96 \\
2.0 & 124 & 4.96 \\
20.0 & 148 & 5.92 \\
F value $^{1}$ & 0.124 & 0.124 \\
Df $^{2}$ & $1, \infty$ & $1, \infty$ \\
F value $^{3}$ & 3.84 & 3.84 \\
\hline
\end{tabular}

Means are based on 25 cells per treatment.

1 Calculated $F$ value.

2 Degrees of freedom for the replicate.

3 Table value which $F$ must equal or exceed to be statistically significant $(P<0.05)$.

* Significant at $(\mathrm{P}<0.05)$ compared to the DMSO control.

significant increases in rates of SCE or delay in cell cycle induced by this insecticide in cultured mammalian cells. Though our data tend to indicate a lack of significant increase in rates of SCE from chlorpyrifos exposure, we have reported a significant increase in SCE rates from exposure to antother organophosphate, Malathion (Herath et al. 1989).

The common structural element of all organophosphates are the phosphorus and carbon as the electrophilic key reactive sites (Wild 1975). Chlorpyrifos and its two primary metabolites, namely 3,5,6-trichloro-2-pyridinol and diethyl-3-5-6-trichloro-2-pyridyl phosphate, have the nucleophilic sites that can cleave the carbon-oxygen bond resulting in alkylation (Wild 1975). Most of the chlorpyrifos is eliminated in animals as 3,5,6-trichloro-2-pyridinol through urine (Marshall and Roberts 1978). Genotoxic investigations of all compounds used widely as insecticide is indeed imperative but particularly those known to be nucleic acid alkylating agents must undergo close scrutiny.

Single acute exposures for a duration of 4- or 24-hours of chlorpyrifos at concentrations ranging from 0.02 to $20 \mu \mathrm{g} / \mathrm{ml}$ did not have statistically singnificant chromsome damage, though the rates of increase of sister chromatid exchanges did reach significance level at $0.02 \mu \mathrm{g} / \mathrm{ml} \mathrm{com}$ pared to one of the two controls. The LD50 (lethal dosage at $50 \%$ kill) for mammals for 
chlorpyrifos ranges from 62 to $6730 \mathrm{mg} / \mathrm{kg}$ body weight (Marshall and Roberts 1978). It therefore seems that chlorpyrifos is an insecticide that causes relatively limited chromosome damage at low dosage exposures. These results must be treated with caution since they do not reflect genotoxic influence from repeated or chronic exposures. Efforts must continue to procure safer compounds that are not reactive to nucleic acids.

\section{Summary}

Chlorpyrifos is one of the widely used organophosphorus insecticides. The compound and two of its main metabolites are known nucleic acid alkylating agents. Potential of the compound as a genotoxic agent was determined on the basis of chromosome damage and rates of sister chromatid exchanges in cultured human lymphocytes. Four treatments $(0.02,0.20$, 2.00 and $20.00 \mu \mathrm{g} / \mathrm{ml}$ ), a solvent control and an untreated control were used in three replications of 4-hour and 24-hour exposures to assess damage to chromosomes. One replication of the four treatments and two controls based on 24-hour exposure was used to determine sister chromatid exchanges. Chromosome damage assessed primarily as gaps and breaks did not increase at a statistically significant level. The trend was almost similar for sister chromatid exchanges though for one of the controls, significance was reached for one treatment level. It seems that short term exposure to chlorpyrifos at these dosages is relatively safe. Efforts however, must continue for procurement of safer compounds that are not reactive to nucleic acids.

\section{References}

Bedford, C. and Robinson, J. 1972. The alkylating properties of organophosphates. Xenobiotica 4: 307-337. Bloom, A. D. ed. 1981. Guidelines for Cytogenetic Studies in Mutagen-exposed Human Populations. March of Dimes Birth Defects Foundation. $163 \mathrm{p}$.

Chen, H. H., Hsue, J. L., Sirianni, S. R. and Huang, C. C. 1981. Induction of sister-chromatid exchanges and cell cycle delay in cultured mammalina cells treated with eight organophosphorus pesticides. Mutat.

Res. 88: 307-316.

Degraeve, N., Chollet, M. and Moutschen, J. 1984. Cytogenetic and genetic effects of sub-chronic treatments with organophosphorus insecticides. Arch. Yoxicol. 55: 66-67.

Herath, J. F., Jalal, S. M., Ebertz, M. J. and Martsolf, J. T. 1989. Genotoxicity of the Organophosphorus Insecticide Malathion based on Human Lymphocytes in culture. Cytologia 54: 101-195.

Latt, S. A., Schreck, R. R., Loveday, K. S. and Shuler, C. F. 1979. In vitro and in vivo analysis of sister chromatid exchange. Pharm. Rev. 30: 501-535.

Margolin, B. H. 1985. Statistical studies in Genetic Toxicology: A perspective from the U.S. National Toxicology Program. Env. Hlth. Perspec. 63: 187-194.

Marshall, W. K. and Roberts, J. R. 1978. Ecotoxicology of Chlorpyrifos. (Ottawa, National Research Council of Canada, 16079).

Muscarella, D. E., Keown, J. F. and Bloom, S. E. 1984. Evaluation of the genotoxic and embryotoxic potential of chlorpyrifos and its metabolites in vivo and in vitro. Environ. Mut. 6: 13-23.

Preston, R., Au, W., Bender, M., Brewen, J., Carrano, A., Heddle, J., Mcfee, A., Wolff, S. and Wasson, J. 1981. Mammalian in vivo and in vitro cytogenetic essays: A report of the U. S. EPA's Gene-Tox Program. Mutat. Res. 87: 143-188.

Roscoe, J. T. 1975. Fundamental Research Statistics for the Behavioral Sciences. New York: Holt, Rinehart, and Winston Inc.

Sobti, R. C., Karishan, A. and Pfaffenberger, C. D. 1982. Cytokinetic and Cytogenetic effects of some agricultural chemicals on human lymphoid cells in vitro: organophosphates. Mutat. Res. 102: 89-102.

Wild, D. 1975. Mutagenicity studies on organophosphorus insecticides. Mutat. Res. 32: 133-150. 